\title{
Kátia Tapety: ora mulher, ora travesti? Gênero, sexualidade e identidades em trânsito no Brasil*
}

Fabiano Gontijo **

\begin{abstract}
Resumo
Servindo-nos da trajetória de Kátia Tapety - a primeira travesti eleita a cargo político no Brasil - e baseando-nos nos estudos seminais de Peter Fry, esboçaremos algumas reflexões sobre as articulações transitivas dos sistemas de representações sobre a sexualidade no Brasil $e$ as maneiras peculiares como sexualidade $e$ gênero, enquanto poderosos marcadores sociais da diferença, se relacionam na base desses sistemas de representações.
\end{abstract}

Palauras-chave: Gênero, Sexualidade, Sistemas de Representações, Travesti, Kátia Tapety, Brasil.

\footnotetext{
* Recebido 21 de dezembro de 2013, aceito em 17 de setembro de 2014.

** Professor de Antropologia no Programa de Pós-Graduação em Antropologia, Instituto de Filosofia e Ciências Humanas, Universidade Federal do Pará; Bolsista de Produtividade em Pesquisa do $\mathrm{CNPq}$ - ao CNPq, agradecemos a bolsa concedida. fgontijo2@hotmail.com
} 
300 Kátia Tapety: ora mulher, ora travesti?

Kátia Tapety: Sometimes Woman, Sometimes Transsexual?

Gender, Sexuality, and Identities in Transit in Brazil

\begin{abstract}
We analyze the biography of Kátia Tapety - the first transsexual to hold political office in Brazil - and, based on the seminal texts of Peter Fry, outline some questions about the systems of representations of sexuality in Brazil and the peculiar ways in which sexuality and gender are (or not) linked.
\end{abstract}

Key Words: Gender, Sexuality, Systems of Representation, Transsexual, Kátia Tapety, Brazil. 


\section{De José a Kátia, vocação de uma trajetória excepcional}

Na região semiárida do Piauí, a uns $20 \mathrm{~km}$ da primeira capital do estado, Oeiras, encontra-se o município de Colônia do Piauí, desmembrado da antiga capital em 1992. ${ }^{1}$ Território de influência política histórica da família Tapety, o vereador que obteve a votação mais expressiva nas primeiras eleições municipais realizadas em 1992 - assim como nas eleições seguintes, em 1996 - foi José Nogueira Tapety Sobrinho. Em 2000, José obteve a segunda votação mais expressiva para a Câmara Municipal, assumindo a presidência da casa durante alguns anos, o que lhe ajudaria à eleição para vice-prefeito numa chapa encabeçada por Lúcia de Fátima Sá para o mandato de 2004 a 2008. Depois de um desentendimento com a prefeita, José se candidatou à Câmara Municipal mais uma vez em 2008, não obtendo votação expressiva. ${ }^{2}$ Em 2012, com o prestígio político abalado, José não se candidatou.

A imprensa divulgou amplamente as eleições de José, principalmente a partir do segundo mandato na Câmara Municipal, o que lhe valeu inúmeros convites para participar de programas de auditório renomados e conceder entrevistas para os mais diversos meios de comunicação nacional e internacional, por um lado; e, por outro, convites para reforçar os quadros, enquanto referência positiva, da militância organizada e do ativismo político de gays, lésbicas, travestis e transexuais no Brasil, em particular aquela parcela vinculada à luta contra a epidemia de HIV/AIDS.

\footnotetext{
1 Muitas reflexões contidas neste artigo provêm de conversas com Ricardo Ximenes (graduando em Ciências Sociais pela Universidade Federal do Piauí, UFPI), Francisca Célia Costa (graduada em Ciências Sociais pela UFPI), Daniel Oliveira da Silva (mestre em Antropologia e Arqueologia pela UFPI) e, sobretudo, com as Profas. Jane Beltrão (Universidade Federal do Pará) e Sandra Nascimento (Universidade Federal do Maranhão) e diversas alunas de Grupo de Pesquisa sobre Gênero, Memória e Identidade (GENI, Universidade Federal do Maranhão). A eles e elas, somos gratos.
}

2 Com a votação obtida, José se tornou suplente. 
Embora seu registro junto ao Tribunal Superior Eleitoral seja José Nogueira Tapety Sobrinho, esse é apenas o nome de batismo daquela que é mais conhecida como Kátia Tapety, a funcionária pública municipal que faz as vezes de parteira, agente de saúde e líder comunitária, mas também de psicóloga e advogada não juramentada e de vaqueira, lavradora e fazendeira aclamada pela população local. Enquanto José entrou para a história da política local como o vereador mais votado das primeiras eleições municipais, Kátia entraria para a história da política nacional como a primeira travesti eleita a cargos públicos.

José nasceu no final da década de 1940, filho daquela que é certamente considerada uma das famílias mais tradicionais do sertão piauiense. ${ }^{3}$ Dos noves filhos, José foi o único que não saiu da pequena vila para estudar nas cidades maiores - Kátia conta que isso se deve ao fato da vergonha que seu pai tinha de seus trejeitos efeminados, já que, desde muito nova, já se identificava "com as coisas de mulher, brincar de boneca, fazer comida, lavar roupa, ajudar a mãe nas costuras" ${ }^{4}$ - embora também auxiliasse seu pai nos afazeres "da roça".

Aos treze anos, José já ousava vestir-se "como mulher", o que ocasionava grande revolta por parte de seu pai, que o tratava com muita violência e evitava apresentar-lhe em público. Conta que os garotos a chamavam de "Zé Muié" ou "mulherzinha", o que, no entanto, não a incomodava, pois "era o que eu queria ser". Seu pai a mantinha sob constante vigilância, principalmente após tê-la

3 Encontramos Kátia, pela primeira vez, em 2004, em sua casa. Numa conversa informal, Kátia contou-nos sua vida de militância e ativismo, enquanto nos mostrava suas fotos ao lado de celebridades políticas e de militantes e ativistas dos movimetos de lésbicas, gays, travestis e transexuais nacionais. A partir desse primeiro encontro, estivemos com Kátia em diversos eventos organizados pelos grupos homossexuais piauienses. Em 2012, resolvemos "oficializar" uma entrevista com Kátia, realizada em sua casa, em Colônia do Piauí. Os relatos que seguem são oriundos dessa entrevista "oficial".

4 Colocaremos entre aspas os exertos do discurso de Kátia, transcritos a partir da entrevista concedida em 2012. 
encontrado inúmeras vezes "no mato com os meninos" mantendo relação sexual, o que lhe valia castigos cada vez mais severos.

Enquanto seus irmãos partiam para estudar nas cidades maiores, Kátia permanecia "na" Colônia, seguindo a "carreira" de seu pai "na roça", como punição, segundo ela, pelo fato de não se adequar ao que seu pai queria que fosse. No entanto, percebe-se que, de fato, José acaba seguindo exatamente o plano de seu pai para tornar-se seu sucessor $e$, até mesmo, "fazer carreira na política". ${ }^{5}$ Kátia informa que seu pai chegou a sequestrá-la quando soube de um "caso" que ela estava tendo com um homem mais velho. José conseguiu fugir por algum tempo, enquanto seu pai teria contratado alguém para matá-lo. Mas, com o adoecimento do pai, José volta para Colônia. Com a morte de seu pai, já maior de idade, José se torna "definitivamente" Kátia nesse momento, passa a morar sozinha na casa da família, na Colônia, já que sua mãe preferiu morar com um dos filhos, em Oeiras, onde a família também tinha propriedades.

Kátia concluiu os estudos por correspondência, já que seu pai não a deixava estudar. Fez curso de auxiliar de enfermagem e se tornou "parteira e arrancadora de dente", além de auxiliar a quem bem recorresse aos seus serviços (de qualquer ordem). Kátia se torna, a partir daí, uma importante referência em saúde na microrregião $e$, sozinha, passa a desenvolver projetos $e$ campanhas de luta contra a disseminação de doenças sexualmente transmissíveis, como HIV/AIDS, principalmente após ter percebido "a olho nu" o incremento do número de casos nos "interiores" por onde passava.

$\mathrm{O}$ fato de conhecer todos os moradores do local e de atender às suas necessidades em saúde e em outros assuntos, fez com que Kátia conseguisse se eleger a cargos públicos sem grandes dificuldades. Kátia se tornou conhecida, assim, por ser a

\footnotetext{
5 Pode-se dizer que a família Tapety, enquanto clã, possui diversas ramificações ou linhagens que se apoderam de microrregiões no entorno de Oeiras. Colônia "naturalmente" o local da linhagem de Kátia - estava fadada a se emancipar de Oeiras e tornar-se, então, importante campo eleitoral dessa linhagem, o que ficou a cargo de Kátia.
} 
primeira travesti eleita a cargo público, não só pelas expressivas votações, mas principalmente quando passou a ser convidada para participar de programas de televisão nacionais - como o Programa do Jô, na Rede Globo, ou os programas de Sílvia Popovic e de Hebe Camargo, em outras redes de televisão - e a ter sua imagem divulgada nacionalmente como a primeira travesti eleita a cargo público. Paralelamente, é convidada para participar do ativismo nacional de combate a doenças sexualmente transmissíveis, no momento em que estavam sendo realizados os primeiros Encontros Nacionais de Travestis e Transexuais que atuavam na luta contra a aids (Entlaids) - embriões do movimento político de travestis $e$ mulheres transexuais no Brasil. A partir daí, conheceu outras travestis e transexuais pelo Brasil afora. Embora nunca tenha "oficialmente" militado por alguma "causa" do movimento homossexual na Colônia, Kátia participou de inúmeros eventos em todo o país e teve sua figura, em alguns momentos, associada a certos pontos da pauta do movimento homossexual como um todo, sendo considerada por algumas militantes e ativistas como "pioneira" no movimento de travestis e transexuais.

Kátia nos conta que teve vários relacionamentos amorosos, dentre eles, um, "ainda novinha", com um ex-prefeito, que lhe ajudou muito oferecendo-lhe um cargo. No entanto, seu relacionamento mais longo, que durou mais de vinte anos, foi com aquele que ela chama de "marido". O marido cuida, ainda hoje, do bar que Kátia abriu para ele ao lado de sua casa. No momento da entrevista, fazia pouco tempo que haviam rompido o relacionamento. Expressando certa mágoa, Kátia afirma que, quando ele veio morar com ela, "era apenas um garoto" e que, ao longo do tempo, foram muitas as "traições por parte dele". De uma dessas "traições" nasceu uma criança, de quem Kátia "cuidou com carinho", como se fosse seu próprio filho. Por isso, diz que, "apesar das traições, o que realmente ocasionou a separação foi a falta de desejo por parte dele". Ela afirma ter mais filhos (crianças que foram entregues aos seus cuidados), um dos quais teria morrido, já adulto, "por complicações renais". No 
entanto, a mágoa dos relacionamentos - ou, pelo menos, do último relacionamento - vem à tona em frases como:

"é por interesse, lógico, [que me querem] se eu não tivesse nada na vida, ninguém queria!" E continua: "Eu falei hoje pro pai dele [referindo-se ao ex-marido] "olha, tu tinha preconceito com teu filho; de todos os filhos teus que saíram pelo mundo, o único que vai sair rico é o que morou com o viado, porque o viado deu condição', falei isso bem aí mesmo!"

No momento da entrevista, Kátia estava às voltas com a possibilidade de uma mudança de partido para se candidatar às eleições de 2014. Paralelamente, continuava a lidar com a "roça" - chegou a convidar-nos para assistir ao parto de um bezerro que ela faria naquele dia! Também seguia com suas atividades de parteira - gerações de crianças nasceram de suas mãos na Colônia - e de auxiliar no combate à disseminação de doenças sexualmente transmissíveis. Ao longo da entrevista, Kátia pegava caixas e mais caixas de fotos desbotadas que retratavam sua trajetória de participação em eventos como palestrante ou como homenageada. - com orgulho, sua foto preferida era provavelmente uma em que posava ao lado de Lula, então Presidente da República. Ao expor suas fotos, parecia querer demonstrar que era uma travesti bem sucedida. Mas, o que víamos no contexto da entrevista, é que Kátia era uma mulher muito requisitada.

Por ser travesti e política, Kátia se tornou uma figura importante para o movimento homossexual brasileiro, mas também foi objeto de estudos acadêmicos e de produção fílmica. A dissertação de mestrado de Luanna Mirella, defendida em 2010 junto ao Programa de Pós-Graduação em Antropologia Social da Universidade de Brasília, aborda a atuação política de Kátia. E o documentário Kátia, de Karla Holanda, lançado em 2012 no Festival de Cinema de Brasília e em 2013 no resto do Brasil retrata sua vida cotidiana. 
306 Kátia Tapety: ora mulher, ora travesti?

Mas, em nossas observações na Colônia, percebemos que Kátia, antes de lhe ser alocada a identidade de travesti, é considerada uma mulher, (quase) como qualquer outra.

\section{Invocando Peter Fry}

Kátia: mulher ou travesti? Gênero ou sexualidade? Ou as categorias de gênero e sexualidade não podem ser pensadas separadamente?

Procuraremos subsídios nos escritos de Peter Fry para esboçar uma resposta, ainda que provisória e incompleta, a essas perguntas um tanto quanto primárias. Em 2014, a pesquisa de campo etnográfica que gerou o artigo seminal de Peter Fry intitulado "Homossexualidade Masculina e Cultos AfroBrasileiros" e publicado inicialmente em inglês sob a forma de comunicação apresentada em congresso completa quarenta anos (Fry, 1982a). A pesquisa partiu dos questionamentos apresentados por Ruth Landes trinta anos antes, publicados em seu polêmico artigo "Matriarcado Cultual e Homossexualidade Masculina" (Landes, 1967). A pesquisa de Fry foi realizada em locais de "cultos de possessão afro-brasileira" na cidade de Belém, capital do Pará (Fry, 1982a:54). Fry infere sobre a relação entre homossexualidade e religiosidade, propondo um esboço do que chamará de sistema de representação hierárquico da sexualidade masculina, comum, segundo ele, em cidades do Norte e Nordeste brasileiros, assim como nas periferias dos grandes centros urbanos industrializados do Sul e do Sudeste e na zona rural brasileira como um todo.

A questão foi aprofundada pelo autor em seu artigo "Da Hierarquia à Igualdade: a construção histórica da homossexualidade no Brasil" (Fry, 1982b), no qual avança apontando que o estudo dos sistemas de representações sobre a sexualidade masculina contribuiria para o estudo da sociedade brasileira como um todo, já que os sistemas de representações são produzidos num contexto político. Analisando o "que as pessoas dizem que fazem e o que acham que deveria ser feito" (Fry, 1982b:88, 89) no tocante à sexualidade, o autor identifica alguns 
modelos a partir da articulação entre sexo fisiológico, "atributos físicos que distinguem machos e fêmeas" (Fry, 1982b:89); papel de gênero, referente "ao comportamento, aos traços de personalidade $e$ às expectativas sociais associadas normalmente ao papel masculino ou feminino"e "comportamento sexual esperado de uma determinada identidade", como atividade $e$ passividade; e orientação sexual, "sexo fisiológico do objeto de desejo sexual" (Fry, 1982b:90,91), ou seja, homossexual, heterossexual ou bissexual).

$\mathrm{O}$ autor desemboca em dois grandes modelos ou sistemas de classificação: por um lado, o modelo hiéraquico, que divide o mundo em "homens" e "bichas" - em que é "homem" quem se comporta sexualmente de maneira ativa e "bicha", quem se comporta de maneira "passiva" e é, logo, associado à feminilidade e ao domínio social da "mulher"; e, por outro, um modelo mais simétrico ou igualitário, que divide o mundo em homossexuais, homens heterossexuais e bissexuais. Enquanto o primeiro modelo encontra sua origem na história colonial brasileira e seria, no momento da escrita do artigo, "bastante hegemônico nas classes mais baixas e no interior do país" (Fry, 1982b:93 - nossos grifos), o segundo modelo, por sua vez, é oriundo do sistema médicocientífico que produz a "condição homossexual" e era (e ainda é) alastrado pelas camadas médias urbanas dos grandes centros brasileiros, representando a modernidade e a vanguarda em termos comportamentais. Os movimentos políticos homossexuais que se desenvolviam nas décadas de 1970 e 1980 no Brasil, no momento em que Fry escrevia seus textos, se serviam fartamente do segundo modelo, o que estaria gerando, naquele momento, uma tensão (política) entre as tendências identitárias dos movimentos $e$ as experiências homossexuais efetivas (mais próximas do modelo hierárquico). ${ }^{6}$

Os escritos de Fry (1982a; 1982b), assim como os de Fry e MacRae (1982) e as obras de Guimarães (2004), Parker (1986),

\footnotetext{
${ }^{6}$ Ver, a respeito da história dos movimentos e dessas tensões, Mac Rae (1982), Mott (1995), Green (2000) e Facchini (2003).
} 
Perlongher (1987), Mott (1987a; 1987b), Muniz de Oliveira (1992), Heilborn (1996; 2004) e Costa (1992), dentre outras, partiram, em maior ou menor grau, das tensões observadas por Fry e acabaram por contribuir decisivamente para a instituição do campo dos estudos sobre (homo)sexualidade no Brasil. Mas, quase sempre, (homo)sexualidade masculina ou com viés masculino... e/ou, sobretudo, urbana.

Até as publicações dos autores citados acima, os estudos sobre (homo)sexualidade no Brasil, de maneira geral, poderiam ser agrupados em três áreas: na primeira, os estudos realizados na área das ciências biomédicas (incluindo-se aí a psicologia e as áreas correlatas), que visavam a demarcação acadêmica das áreas científicas no Brasil, tipologizando as práticas - e identidades a elas atreladas - "patológicas"; na segunda, os estudos realizados na grande área das ciências humanas (incluindo-se aí a filosofia), tipologizando as práticas - e identidades a elas atreladas "normais", com descrições de sociabilidades "anormais"; enquanto os primeiros estudos são continuados, os outros são esporádicos, sem grandes efeitos ou com efeitos efêmeros na consolidação tanto da área das ciências humanas, como de um campo de saberes autônomo sobre sexualidades; enfim, na terceira, os estudos na área de literatura (incluindo-se aí os ensaios jornalísticos realistas e naturalistas), com um número relativamente extenso de obras que abordam direta ou indiretamente (nomeadamente ou não) as experiências sexuais diversas $e$ particulares de setores da população brasileira e a relação dessas experiências com os modos de vida desses setores, seja como objeto principal da obra ou como elemento tangencial ao objeto principal, seja como fruto de uma reflexão moral (O Bom Crioulo, de Adolfo Caminha) ou como relato de vivências mundanas divergentes, estigmatizadas e periféricas (Capitães de Areia, de Jorge Amado).

Enquanto os estudos médicos delineavam as sexualidades "divergentes" como problemas a serem corrigidos e tratados, as ciências humanas as exibiam como curiosidades das camadas populares, geralmente negras, periféricas, umbandistas e 
prostituídas; a literatura, por sua vez, as viam como fatos $e$ vivências a serem relatados, ainda que com subterfúgios ardilosos para a emissão de juízos morais (quase sempre de cunho médico e/ou filosófico). ${ }^{7}$ Com algumas poucas exceções, as experiências de lésbicas e de travestis e transexuais, não pareciam ser o alvo de interesse desses estudos. Nem as experiências homossexuais fora do eixo dos grandes centros urbanos nacionais ou na zona rural...

\section{Evocando lacunas}

Os estudos instituidores de uma nova abordagem das (homo)sexualidades de Fry aparecem no mesmo momento em que os movimentos homossexuais brasileiros estão se estruturando, assim como outros movimentos sociais - dentre os quais, o feminista - baseados na igualdade de direitos de indivíduos. Esses movimentos, segundo o autor, "são constitutivos do processo de diferenciação da sociedade brasileira e surgem da experiência social dessas camadas da classe média em formação" (Fry, 1982b:110). Mas, se o movimento homossexual se desenvolve em diálogo com a produção acadêmica (geralmente crítica em relação ao movimento, como se nota no artigo seminal de MacRae, de 1982), o movimento de lésbicas, que se destaca em certa medida do movimento homossexual como um todo nesses primeiros momentos (Facchini, 2003), não parece interagir com estudos acadêmicos, pelo simples fato de (quase) não haver estudos sobre a questão, dando a entender não considerarem relevante estudar as experiências lésbicas ou como se estudar a (homo)sexualidade masculina já abrangesse "naturalmente" as

\footnotetext{
7 Para as referências acerca da genealogia dos estudos sobre (homo)sexualidade no Brasil, ver o próprio artigo de Fry (1982b), mas também os de Arney, Fernandes e Green (2003); e ainda, para entender a maneira como a obra de Fry abriu novos espaços para a instituição do campo dos estudos sobre (homo)sexualidade, sobre novas bases teóricas e metodológicas, ver também Facchini (2003) e Carrara e Simões (2007).
} 
(então tão desconsideradas) especificidades lésbicas. ${ }^{8}$ Os estudos sobre travestis, mas também sobre as experiências homossexuais de modo geral nas zonas rurais ou interioranas, eram tão raros ou inexistentes quanto os estudos sobre as especificidades lésbicas.

Após os trabalhos pioneiros de Mott (1987) e Muniz de Oliveira (1992), as representações sobre a sexualidade feminina $e$ as experiências lésbicas começam a ganhar certa visibilidade, ainda que tímida, a partir da década de 2000, quando algumas comunicações são apresentadas em congressos e encontros, artigos são publicados em periódicos $e$ anais de eventos $e$ dissertações de mestrado e teses de doutorado são defendidas em programas de pós-graduação na área das ciências humanas (e afins) nos grandes centros universitários das regiões Sudeste e Sul do Brasil. ${ }^{9}$ Por outro lado, além do trabalho também pioneiro de Silva (1993), despontam, igualmente na década de 2000, com muito vigor, os estudos sobre travestis e transexuais, como os de Bento (2006), Kullick (2008) ou Pelúcio (2009). ${ }^{10}$ Se, desde os textos seminais de Fry, o campo dos estudos sobre homossexualidade se constitui com pesquisas que abordam geralmente a realidade de homens homossexuais dos grandes centros urbanos, dissociando sexualidade de gênero, nos estudos sobre travestilidades $e$ transexualidade, percebe-se um interesse maior pela relação entre os marcadores de sexualidade e de gênero para o melhor entendimento das realidades "trans".

Alguma lacuna ainda persiste, porém, no que diz respeito às experiências homossexuais em contextos que chamaremos

\footnotetext{
${ }^{8}$ Fry, em seus dois textos fundamentais (1982a e 1982b), explicitou sua opção de cunho metodológico (mas também político) pelo estudo da sexualidade masculina.

${ }^{9}$ Dentre essas dissertações e teses, destacam-se os trabalhos de Almeida (2005), Lacombe (2005), Gomide (2006), Facchini (2008) e Meinerz (2011a; 2011b), para citar somente alguns.

${ }^{10}$ Alguns estudos sobre a diversidade sexual e de gênero no contexto das periferias dos grandes centros urbanos - onde predominaria, segundo Peter Fry, o modelo hierárquico - foram realizados ao longo das duas últimas décadas, como os de Moutinho (2006), Aguião (2007) e Lopes (2011), dentre outros.
} 
provisoriamente, a partir daqui, de "periféricos", ou seja, nas regiões Norte e Nordeste, nas áreas rurais ou menos urbanizadas e em territórios etnicamente diferenciados (quilombos $e$ comunidades indígenas) - onde predominava, segundo Fry (1982b), o modelo hierárquico. ${ }^{11}$ Em Gontijo (2013), mostramos que, no que diz respeito aos estudos rurais, parece que a maior parte dos artigos e textos que analisamos e que tratam das relações de gênero está voltada ora para a organização social vinculada aos aspectos econômicos da vida no campo, ora para as questões morais relativas à família e aos arranjos familiares camponeses. Gênero aparece quase sempre na forma da mulher trabalhadora e/ou militante ou dos papéis familiares. A sexualidade nunca aparece, com as raras exceções citadas na nota de rodapé 12 . Por outro lado, no que diz respeito aos estudos de gênero e sexualidade, quando há articulação com a ruralidade, nota-se um grande número de artigos e textos que abordam, num primeiro momento, a condição da mulher camponesa (reprodutora e eventualmente produtora), às vezes vinculada aos movimentos sociais no campo, e/ou, em seguida, as relações de poder que permeiam as relações de gênero e as transformações dessas relações no mundo rural contemporâneo. A sexualidade (a)parece relegada à vida urbana: o tal "indizível das sociedades camponesas", de que trata Ferreira (2006) em sua dissertação de mestrado. ${ }^{12}$

A sexualidade e, mais particularmente, a diversidade sexual $e$ de gênero $e$ as práticas sexuais que podem se tornar marcadores

${ }^{11}$ Essa lacuna vem sendo preenchida pouco a pouco pelos estudos iniciados por Ferreira (2006) e Nascimento (2006) e pelo trabalho que nós mesmos estamos desenvolvendo desde 2010/2011 (Gontijo \& Costa, 2012; Gontijo, 2013).

${ }^{12}$ Nos estudos rurais, a invisibilização do outro no que diz respeito às práticas sexuais e às construções identitárias ligadas a essas práticas parece concernir também à criança e até mesmo, em menor grau, ao negro, o que é confirmado, não somente pelo trabalho de Ferreira (2006) e Nascimento (2006, 2012), como apontamos acima, mas também pelo textos de Maria Isabel Ferraz Pereira Leite (1996) e, mais recentemente, de Jairo Barduni Filho, Ana Louise de Carvalho Fiúza, Erika Oliveira Amorim e Adriana Maria da Silva Costa (Barduni Filho et alii., 2010). 
sociais da diferença nas pesquisas sobre o mundo rural não foram transformadas em objetos de estudo per se por diversas razões. Talvez a principal dessas razões seja a própria agenda de pesquisas, tanto nos estudos rurais, como nos estudos de gênero $e$ sexualidade, pautada por outros interesses de pesquisa ligados a certas tradições intelectuais (muitas vezes, a montagem da agenda se faz em acordo com demandas oriundas dos mais diversos pontos do campo de força em jogo nas ciências sociais). No caso dos estudos rurais, em algumas tradições intelectuais que buscam entender as sociedades camponesas como sistemas sociais específicos, a economia e a política se tornam dimensões mais privilegiadas do que a sexualidade, entendida, esta última, como secundária (pensamos aqui, como exemplo, numa certa tradição já clássica desenvolvida, por um lado, por Eric Wolf e Sydney Mintz, e, por outro, por Henri Mendras).

\section{(Re)evocando categorias}

No âmbito de uma pesquisa mais ampla ${ }^{13}$ que visa a delimitação do universo simbólico - socialmente construído $e$ culturalmente formulado - que serve de referência para a ordenação das representações sobre sexualidade e para a organização das experiências homossexuais nesses contextos "periféricos", realizamos, ao longo de 2012 e 2013, algumas entrevistas e observações que nos permitiram reconstituir as trajetórias de vida $e$ as redes de sociabilidade de travestis nos "interiores" do Piauí, dentre as quais, Kátia Tapety. ${ }^{14}$

Assim, ao perceber que nos estudos rurais pouca (ou nenhuma) atenção foi dada às sexualidades e que nos estudos

\footnotetext{
${ }^{13}$ Agradecemos ao Conselho Nacional de Desenvolvimento Científico e Tecnológico (CNPq) pela Bolsa de Produtividade em Pesquisa concedida para a realização dessa pesquisa e pelos recursos disponibilizados através da Chamada MCTI/CNPq/MEC/CAPES 43/2013.

${ }^{14}$ As entrevistas foram tratadas como narrativas biográficas (Bauman, 1986) ou etnobiografias (Feal, 1990; Gonçalves et al., 2012) focadas nas performances de gênero (Butler, 1990).
} 
sobre a diversidade sexual e de gênero pouco (ou nenhum) interesse foi demonstrado às experiências não urbanas, trazemos elementos, com a apresentação da trajetória selecionada de Kátia Tapety, para incitar a reflexão sobre a operacionalidade dos modelos propostos por Fry para a compreensão das experiências sustentadas por sistemas de representações sobre a sexualidade nos dias de hoje, em contextos pouco considerados, como no mundo rural.

Percebe-se, com a trajetória de Kátia, que, em determinadas interações, ela pode "acionar" performaticamente a identidade de gênero de mulher para tornar-se um sujeito inteligível (Butler, 1990) na interação em questão - é assim, por exemplo, quando visita os moradores da Colônia $e$ atende aos pedidos de auxílio, seja com seus conhecimentos da área de saúde, seja com seus afetos femininos. Mas em outras interações Kátia "aciona" performaticamente a identidade desviante de travesti, também para tornar-se um sujeito inteligível - embora essa inteligibilidade esteja, aqui, baseada no seu caráter transgressor. Neste último caso, a transgressão se torna inteligibilidade acionada perante os pares, quando Kátia está no espaço da militância e do ativismo, o que lhe outorga o título de personalidade pública - "a primeira travesti eleita a cargo público no Brasil".

Por um lado, na Colônia, haveria uma Kátia-mulher, vinculada ao sistema de representações na base do modelo hierárquico de gênero, e, por outro, no mundo, a Kátia-travesti, vinculada a um sistema de representações que parece se encontrar entre o modelo hierárquico e o modelo simétrico, já que, nesse caso, "travesti" se torna uma categoria política muito próxima da categoria "homossexual" do sistema simétrico de classificação (quando acionada por sujeitos mentores do movimento homossexual na virada da década de 1970 para 1980, como sugere MacRae em seu artigo de 1982). Em realidade, mais do que "duas Kátias", teríamos uma Kátia que é atravessada pela 
transitoriedade das categorias, o que marca, assim, suas maneiras de constituir-se no mundo em suas interações cotidianas. ${ }^{15}$

A excepcionalidade da trajetória de Kátia - assim como outras trajetórias extraordinárias, em outros contextos de estudos, como as de Leila Diniz (Goldenberg, 1996) e Consuelo Caiado (Kofes, 2001), ou até mesmo as de Janaína Dutra, "a primeira travesti advogada do Brasil", Luma Andrade, "a primeira travesti doutora", ou Jovanna Baby, "a primeira grande militante/ativista travesti do Nordeste" 16 - nos fornece chaves privilegiadas para a compreensão dos mecanismos de articulação entre as categorias de diferenciação $e$ as estruturas que geram e reproduzem a heteronormatividade $e$ as desigualdades a ela atreladas. A maneira como Kátia combina os sistemas de representações sobre sexualidade e as categorias de gênero e sexualidade a partir do mundo rural demonstra que há lugar para arranjos que destoem do modelo hegemônico e que negociações (públicas) estão sempre em jogo, para além da hegemonia percebida ora do modelo hierárquico ${ }^{17}$, ora do modelo igualitário. Esses dois modelos que particularizam as representações sobre sexualidade no Brasil mostram-se, assim, extremamente atuais em suas

\footnotetext{
${ }^{15}$ Será que poderíamos avançar que os insucessos políticos de Kátia da virada das décadas de 2000 para 2010 aos dias atuais seriam atribuídos ao fato de haver certa confusão entre uma e outra identidade acionada, em detrimento da Kátia-mulher, em territórios onde até então ela predominava - e era essa Kátiamulher que dava a Kátia seus créditos políticos? Parece que a tensão entre as forças centrípetas (que ligam Kátia a Colônia e ao mundo rural) e as forças centrífugas (que ligam Kátia aos movimentos sociais de travestis e transexuais $e$ ao cenário nacional da militância e do ativismo) está deseguilibrando o "rapport de force" e tornando Kátia cada vez mais "só" Kátia-travesti.

${ }^{16}$ Para esses três últimos casos, reporte-se a Sampaio (2013).

${ }^{17}$ Nas entrevistas realizadas com travestis que não têm trajetórias "excepcionais" por não terem se envolvido com os movimentos sociais de travestis e transexuais ou com a política partidária, por exemplo, nota-se nitidamente a persistência das representações oriundas do modelo hierárquico, embora com nuanças e matizes características dos dias atuais (em comparação com aquelas da década de 1970, em que Peter Fry pesquisou e escreveu). Para a trajetória de algumas dessas travestis menos "visibilizadas" que vivem no mundo rural piauiense, ver nosso artigo de 2012, publicado com Francisca Célia Costa (Gontijo \& Costa, 2012).
} 
múltiplas nuanças e interseções, se levarmos em consideração as consequências das mudanças sociais e culturais ocorridas desde os primeiros escritos de Peter Fry na década de 1970.

\section{Referências bibliográficas}

AguiÃo, Sílvia. "Aqui nem Todo Mundo é Igual!" Cor, Mestiçagem e Homossexualidades numa Favela do Rio de Janeiro. Dissertação de Mestrado, Instituto de Medicina Social, Universidade Estadual do Rio de Janeiro, 2007.

AlmEIDA, Guilherme. Da Invisibilidade à Vulnerabilidade: percursos do 'corpo lésbico' na cena brasileira face à possibilidade de infecção por DST e AIDS. Tese de Doutorado, Instituto de Medicina Social, Universidade Estadual do Rio de Janeiro, 2005.

ARNEY, Lance; FeRnANDES, Marisa; GREEN, James. Homossexualidade no Brasil: uma bibliografia anotada. Cadernos AEL (10, 18/19), Campinas, Arquivo Edgar Leuenroth/Unicamp, 2003, pp.317-348.

BARDUNI Filho, Jairo et alii. A Transformação das Relações Afetivas no Meio Rural: breves anotações das relações oficiosas, e oficiais na perspectiva de gênero. In: Anais Do Viii Congreso Latinoamericano de Sociología Rural (ALASRU), Porto de Galinhas, PE, 2010. Disponível em: http://www.gerar.ufv.br/publicacoes/a transformacao_das_relacoes_\%20afetiv as no meio_rural breves_anotacoes_das_relacoes_oficiosas e _of.pdf.

BAUMAN, Richard. Story, Performance and Event: contextual studies of oral narrative. Cambridge, Cambridge University Press, 1986.

BENTO, Berenice. A Reinvenção do Corpo: sexualidade e gênero na experiência transexual. Rio de Janeiro, Garamond, 2006.

BUTLER, Judith. Gender Trouble: feminism and the subversion of the identity. Nova Iorque, Routledge, 1990.

CARRARA, Sérgio; SimÕES, Júlio. Sexualidade, Cultura e Política: a trajetória da identidade homossexual masculina na antropologia brasileira. Cadernos Pagu (28), Campinas, Núcleo de Estudos de Gênero-Pagu/Unicamp, 2007, pp.65-99. 
316 Kátia Tapety: ora mulher, ora travesti?

CostA, Jurandir Freire. A Inocência e o Vício. Rio de Janeiro, RelumeDumará, 1992.

FACCHINI, Regina. Movimento Homossexual no Brasil: recompondo um histórico. Cadernos AEL (10, 18/19), Campinas, Arquivo Edgar Leuenroth/Unicamp, 2003, pp.81-124.

- Entre Umas e Outras: mulheres, (homo)sexualidades e diferenças na cidade de São Paulo. Tese de Doutorado, Ciências Sociais, Unicamp, 2008.

FEAL, Rosemary G. Spanish American Ethnobiography and the Slave Narrative Tradition: "Biografía de un Cimarrón" y "Me Llamo Rigoberta Menchu". Modern Language Studies (20, 1), 1990, pp.100-111.

FERREIRA, Paulo Rogers. Os Afectos Mal-Ditos: o indizível das sociedades camponesas. Dissertação de Mestrado, Antropologia Social, Universidade de Brasília, 2006.

FRY, Peter. Homossexualidade Masculina e Cultos Afro-Brasileiros. In: FRY, Peter. Para Inglês Ver: identidade e política na cultura brasileira. Rio de Janeiro, Zahar, 1982a, pp.54-86.

Da hierarquia à Igualdade: a construção histórica da homossexualidade no Brasil. In: . Para Inglês Ver: identidade e política na cultura brasileira. Rio de Janeiro, Zahar, 1982b, pp.87-115.

Fry, Peter, MACRAE, Edward. O Que é Homossexualidade. São Paulo, Brasiliense, 1983.

GoldenBerg, Mirian. Toda Mulher é Meio Leila Diniz. Rio de Janeiro, Record, 1996.

GOMIDE, S. Representações das Identidades Lésbicas na Telenovela "Senhora do Destino". Dissertação de Mestrado, Comunicação, Universidade de Brasília, 2006.

GONÇALVES, Marco Antônio et alii. (orgs.). Etnobiografia - subjetivação e etnografia. Rio de Janeiro, 7 Letras, 2012.

GonTIJO, Fabiano. Diversidade Sexual e de Gênero no Contexto Rural Brasileiro: algumas reflexões preliminares. Revista FSA (10, 2), Teresina-PI, 2013, pp.84-100. 
GonTIJO, Fabiano e COSTA, Francisca Célia. "Ser Traveco é Melhor que Mulher": considerações preliminares acerca das discursividades do desenvolvimentismo e da heteronormatividade no mundo rural piauiense. Bagoas: revista de estudos gays, gênero e sexualidades (8), Natal, 2012.

GREEN, J. "Mais Amor e Mais Tesão": a construção de um movimento brasileiro de gays, lésbicas e travestis. Cadernos Pagu(15), CampinasSP, Núcleo de Estudos de Gênero-Pagu/Unicamp, 2000, pp. 271-295.

GuimarãES, Carmen Dora. O Homossexual Visto por Entendidos. Rio de Janeiro, Garamond, 2004 [1977].

HEILBORN, Maria Luiza. Ser ou Estar Homossexual: dilemas de construção de identidade social. In: PARKER, Richard e BARBOSA, Regina (orgs.). Sexualidades Brasileiras. Rio de Janeiro, RelumeDumará, 1996.

Dois é Par: conjugalidade, gênero e identidade. Rio de Janeiro, Garamond, 2004 [1992].

KofES, Suely. Uma Trajetória em Narrativas. Campinas-SP, Mercado das Letras, 2001.

KuLICK, Don. Travesti: prostituição, sexo, gênero e cultura no Brasil. Rio de Janeiro, Fiocruz, 2008.

LACOMBE, Andrea. "Pra Homem Já Tô Eu; masculinidades e socialização lésbica em um bar no centro do Rio de Janeiro. Dissertação de Mestrado, Antropologia Social, PPGAS/MN/UFRJ, 2005.

LANDES, Ruth. Matriarcado Cultual e Homossexualidade Masculina. In: LANDES, Ruth. A Cidade das Mulheres. Rio de Janeiro, Civilização Brasileira, 1967, pp.215-235.

LOPES, Paulo Victor Leite. Sexualidade e Construção de Si em uma Favela Carioca: pertencimentos, identidades, movimentos. Dissertação de Mestrado, Antropologia Social, PPGAS/MN/UFRJ, 2011.

MACRAE, Edward. Os Respeitáveis Militantes e as Bichas Loucas. In: Eulálio, A. et alii. (orgs.). Caminhos Cruzados. São Paulo, Brasiliense, 1982, pp.99-111. 
318 Kátia Tapety: ora mulher, ora travesti?

MEINERZ, Nádia. Entre Mulheres: etnografia sobre relações homoeróticas femininas em segmentos médios urbanos na cidade de Porto Alegre. Rio de Janeiro, EdUERJ, 2011a.

- Mulheres e Masculinidades: etnografias sobre afinidades de gênero no contexto de parcerias homoeróticas entre mulheres de grupos populares em Porto Alegre. Tese de Doutorado, Antropologia Social, Universidade Federal do Rio Grande do Sul, 2011b.

MiRELlA, Luanna. Localidade ou Metrópole? Demonstrando a Capacidade de Atuação Política das Travestis no MundoComunidade. Dissertação de Mestrado, Antropologia Social, Universidade de Brasília, 2010.

MotT, Luiz. Dez Viados em Questão: tipologia dos homossexuais da Bahia. Salvador, Ed. Bleff, 1987a. Editora, 1987b.

. O Lesbianismo no Brasil. Porto Alegre, Mercado Aberto

. The Gay Movement and the Human Rights in Brazil. In: MuRRAY, S. O. (org.). Latin American Male Homosexualities. Albuquerque, New Mexico University Press, 1995.

MouTiNHO, Laura. Negociando com a Adversidade: reflexões sobre "raça", (homo)sexualidade e desigualdade social no Rio de Janeiro. Revista Estudos Feministas, (14, 1), Florianópolis, UFSC, 2006, pp.103-116.

Muniz DE OliveIRA, Jacqueline. Mulher com Mulher dá Jacaré": uma abordagem antropológica da homossexualidade feminina. Dissertação de Mestrado, Antropologia Social, PPGAS/MN/UFRJ, 1992.

NASCIMENTO, Silvana de Souza. Faculdades Femininas e Saberes Rurais. Uma Etnografia sobre Gênero e Sociabilidade no Interior de Goiás. Tese de Doutorado, Ciência Social (Antropologia), Universidade de São Paulo, 2006.

. Homem com Homem, Mulher com Mulher: paródias sertanejas no interior de Goiás. Cadernos Pagu (39), Campinas-SP, Núcleo de Estudos de Gênero-Pagu/Unicamp, 2012, pp.367-402.

PARKER, Richard. Masculinity, Feminility, and Homosexuality: on the anthropological interpretation of the sexual meanings in Brazil. In: 
BlACKWOOD, Evelyn (org.). Anthropology and Homosexual Behavior. Nova Iorque, The Haworth Press, 1986, pp.65-84.

PElÚCIO, Larissa. Abjeção e Desejo: uma etnografia travesti sobre o modelo preventivo de Aids. São Paulo, Annablume, 2009.

PEREIRA, Maria Isabel Ferraz. Crianças no Campo: os mudos da história? Revista Estudos Sociedade e Agricultura (6), Rio de Janeiro, 1996, pp.170-191.

Perlongher, Néstor. O Negócio do Michê: prostituição viril em São Paulo. São Paulo, Brasiliense, 1987.

SAMPAIO, Juciana. As Desbravadoras do Sertão: travestis "pioneiras" do Nordeste brasileiro. Paper apresetnado no XVI Congresso da Sociedade Brasileira de Sociologia, 10 a 13 de setembro de 2013, Salvador, Universidade Federal da Bahia.

SILVA, Hélio. Travesti: a invenção do feminino. Rio de Janeiro, RelumeDumará, 1993.

\section{Referência fílmica}

HolandA, Karla. Kátia. Rio de Janeiro, 2012. Produção: Leonardo Mecchi, Alcilene Cavalcante, Karla Holanda, 74 min. 